\title{
LIPID ABNORMALITY IN HYPERTENSIVE SUDANESE PATIENTS IN SHENDI LOCALITY, SUDAN
}

Eltigani MA ${ }^{1}$, Barri $\mathrm{AM}^{2}$, Khalid Hussein Bakheit ${ }^{3}$, Haghamad Allzain ${ }^{4}$, Hijazi Mohamed Ahmed $^{5}$, Ibrahim Bakhit ${ }^{6}$, Rashid Eltayeb ${ }^{7}$

$1,2,4,{ }^{7}$ Department of biochemistry, ${ }^{5}$ Department of Nursing, ${ }^{6}$ Department of histopathology, Faculty of Medicine, Shendi University, Shendi, SUDAN

${ }^{3}$ Department of biochemistry, Faculty of Medicine, University of Tabuk, Tabuk, SAUDI ARABIA

\section{Abstract:}

Hypertension is commonly associated with other cardiovascular risk factors, such as obesity, diabetes, and dyslipidaemia. The presence of these cardiovascular risk factors and the resulting endothelial dysfunction may play a role in the pathophysiology of hypertension. Dyslipidaemia, a strong predictor of cardiovascular disease.

This cross-sectional study was conducted at Shendi locality from February 2011 to July 2012. The patients underwent a clinical assessment, which included history (a questionnaire) and clinical examination. 100 hypertensive patients. The age limits was 40 to 60 years.

There was sharp and definite increase in the percentage of patients having $>200 \mathrm{mg} / \mathrm{dl}$ total cholesterol after four years of diabetes mellitus from (28-34\%) to (41\%). There was a sharp increase in the percentage of patients having $>150 \mathrm{mg} / \mathrm{dl}$ of low density lipoproteins after 6 years of diabetes mellitus from (\%9-8) to (14.2\%). There was also an increase in the percentage of patients having $<160 \mathrm{mg} /$ dl of triglycerides after four years of diabetes mellitus from $53 \%$ to $61 \%$ of diabetes.

Increasing lipid abnormality of hypertensive is associated with higher incidence of CAD.

Keywords:

Hypertension, Lipid profile, Dyslipidemia, cardiovascular risk factors, cardiovascular disease

Cite This Article: Eltigani MA, Barri AM, Khalid Hussein Bakheit, Haghamad Allzain, Hijazi Mohamed Ahmed, Ibrahim Bakhit, and Rashid Eltayeb, "LIPID ABNORMALITY IN HYPERTENSIVE SUDANESE PATIENTS IN SHENDI LOCALITY, SUDAN" International Journal of Research - Granthaalayah, Vol. 3, No. 6(2015): 1-6.

\section{INTRODUCTION}

Heart disease or cardiovascular disease is defined as the class of disease that involved the cardiac or blood vessels including arteries and veins. Although the term technically refers to any disease that affects the cardiovascular system, it is usually to refer to those related to atherosclerosis and 


\section{INTERNATIONAL JOURNAL of RESEARCH -GRANTHAALAYAH

arterial disease since they shared similar conditions of causes, mechanisms and treatments (1). The primary underlying disease process that leads to atherosclerosis is the deposition of lipid on the arterial surface progress to form plaques that reduced blood flow and induced blood clots that blocked flow entirely (2). Most countries face high and increasing rates of cardiovascular disease. In United States, mortality from heart and hypertensive diseases was greater than mortality from neoplasm.

In recent years, cardiovascular risk in women has been increasing and has killed more women than breast cancer (3). The estimated age-adjusted mortalities of cardiovascular disease in US is 152.1 per 100,000 in year 2002 and is 48.3 in Taiwan 2005 (4). By the time that heart problems are detected, the underlying causes, atherosclerosis, is usually quite advanced, have progressed for decades (5). Therefore increased emphasis on preventing atherosclerosis by modifying risk factors is remained important.

\section{MATERIALS AND METHODS}

This study was conducted at Shendi locality to estimate the lipid profile abnormality among hypertensive patients in the period February 2011 to July 2012. The study included (100) patients. Their ages range from (40-60 years). Blood samples were obtained after an overnight fast. Five $\mathrm{ml}$ of venous blood were taken from antecubital vein by plastic disposable syringes. The blood was then transferred into a plane glass tubes. After one hour at room temperature (after clot retraction) centrifugation of the blood was done at a relative centrifugal force of 1000 $\mathrm{g}$ for 5 minutes. Afterward, sera were removed by disposable pasture pipettes and transferred into glass containers. Sera were stored at $\left(-20^{\circ} \mathrm{C}\right)$ to be analyzed in patches. Serum total cholesterol (TC), high density lipoprotein-cholesterol (HDL-C), low density lipoproteincholesterol (LDL-C), triglyceride (TG) and plasma fasting glucose were measured. Height, weight and blood pressure were done for all participants in this study. Clinical data were collected through a questionnaire the (SPSS) version (11.5) program was used for data analysis. All the data were presented as the mean \pm SD.

Inclusion criteria: hypertensive, peoples of age between 40 -60 years of either sex. Exclusion Criteria: No smokers, non-diabetic.

\section{RESULTS}

Table 1: Distribution of patients according to sex

\begin{tabular}{|l|l|l|l|}
\hline \multirow{2}{*}{ Groups } & male & female & Total \\
\cline { 2 - 4 } & Frequency $(\boldsymbol{\%})$ & Frequency $(\boldsymbol{\%})$ & $\mathrm{N}(\%)$ \\
\hline hypertensive & 23 & 77 & 100 \\
\hline Control group & 73 & 27 & 100 \\
\hline
\end{tabular}




\section{INTERNATIONAL JOURNAL of RESEARCH -GRANTHAALAYAH

Table 2: Distribution of patients according to age

\begin{tabular}{|c|c|c|c|c|}
\hline \multirow{2}{*}{ Groups } & 21-40yrs & 41-60yrs & $\begin{array}{l}\text { More than } \\
\text { 60yrs }\end{array}$ & Total \\
\hline & $\begin{array}{l}\text { Frequency } \\
(\%)\end{array}$ & $\begin{array}{l}\text { Frequency } \\
(\%)\end{array}$ & $\begin{array}{l}\text { Frequency } \\
(\%)\end{array}$ & $\mathrm{N}(\%)$ \\
\hline hypertensive & 8 & 54 & 38 & 100 \\
\hline Control group & 36 & 48 & 16 & 100 \\
\hline
\end{tabular}

Table 3: Correlation parameters of patients compared with control group

\begin{tabular}{|c|c|c|c|}
\hline \multirow{2}{*}{\multicolumn{2}{|c|}{ Parameter }} & \multicolumn{2}{|c|}{ Hypertensive } \\
\hline & & \multirow{2}{*}{\begin{tabular}{|l|} 
Mean \pm SD \\
$140.7 \pm 18.3$
\end{tabular}} & $P$ value \\
\hline \multirow{2}{*}{ Pair 1} & Systolic pressure & & \multirow{2}{*}{$.000^{*}$} \\
\hline & Systolic pressure (Control) & $124.7 \pm 14.2$ & \\
\hline \multirow{2}{*}{ Pair 2} & Diastolic pressure & $86.9 \pm 11.1$ & \multirow{2}{*}{$.000^{*}$} \\
\hline & $\begin{array}{l}\text { Diastolic } \quad \text { pressure } \\
\text { (Control) }\end{array}$ & $80.4 \pm 8.4$ & \\
\hline \multirow[t]{2}{*}{ Pair 3} & Total cholesterol & $4.9 \pm 0.9$ & \multirow{2}{*}{.083} \\
\hline & Total cholesterol (Control) & $4.7 \pm 1$ & \\
\hline \multirow[t]{2}{*}{ Pair 4} & HDL & $1.8 \pm 0.7$ & \multirow{2}{*}{$.000^{*}$} \\
\hline & HDL (Control) & $1.3 \pm 0.9$ & \\
\hline \multirow[t]{2}{*}{ Pair 5} & LDL & $2.4 \pm 1.3$ & \multirow{2}{*}{$.000^{*}$} \\
\hline & LDL (Control) & $3.1 \pm 1.2$ & \\
\hline \multirow[t]{2}{*}{ Pair 6} & TG & $1.4 \pm 0.5$ & \multirow{2}{*}{.454} \\
\hline & TG (Control) & $1.5 \pm 0.7$ & \\
\hline
\end{tabular}

${ }^{*} t$ - test $P<0.05$ is highly significant.

${ }^{* *} t$ - test $P<0.05$ is significant

Table 4: Age, duration of diabetes and anthropometric characteristic of study population

\begin{tabular}{|l|l|}
\hline anthropometric & $\begin{array}{l}\text { (hypertensive) } \\
\text { Mean } \pm \text { SD }\end{array}$ \\
\hline A 8 e (year) & $53.7 \pm 10.8$ \\
\hline Duration (year) & $7.5 \pm 5.5$ \\
\hline
\end{tabular}




\section{INTERNATIONAL JOURNAL of RESEARCH -GRANTHAALAYAH

\section{DISCUSSION}

In hypertensive group the study showed the systolic pressure, diastolic pressure to be significantly increased $(\mathrm{P}=0.000)$, also the mean lipid profile with the normal range compared to control group but the percent distribution of lipid profile in this group as follows: $62 \%$ of patients with dyslipidaemia, (15\%) abnormal (TC/ HDL-C) ratio, (40\%) (TC) (>5.2) mmol/l.

Many prospective studies demonstrates that higher levels of plasma (TC), (non-HDL-C), and the (TC/ HDL-C) ratio are independently associated with a subsequent increased risk of incident hypertension in apparently healthy men and that higher levels of (HDL-C) are associated with a decreased risk of incident hypertension. Elevated lipid levels appear to predate the onset of hypertension by years. The relationship between lipids and hypertension is preserved even after adjustment for multiple confounders and after the exclusion of men with diabetes and obesity(7). Lipids and BP have been associated in several cross-sectional studies(8). Castelli and Anderson(9) found that (BP) and serum cholesterol were strongly correlated among hypertensive patients, which led to early recommendations to treat elevated cholesterol in patients with hypertension (10). Gaziano et al (11) also noted a potential interaction between elevated cholesterol and hypertension in the development of MI that suggested a direct relationship rather than the effect of (2) independent predictors.

A few smaller studies have looked prospectively at the relationship between plasma lipids and the future development of hypertension. A (7) years follow up of (1039) initially nondiabetic, nonhypertensive subjects from the San Antonio Heart Study suggested that risk factors for atherosclerosis, including triglycerides, also predicted hypertension (12). A prospective study of (1482) adults in Utah followed for (7) years with (40) cases of incident hypertension reported a significant increase in triglycerides (110) $\mathrm{mg} / \mathrm{dL}$ and a non significant of (HDL-C) (11) $\mathrm{mg} / \mathrm{dL}(13)$. Would expect that if dyslipidaemia played a role in the development of hypertension, then treating dyslipidaemia would have some effect on (BP).

In this regard a recently reported study by Dr. Howard D. Sesso and colleagues at Harvard Medical School in Boston showing that dyslipidaemia is linked to development of hypertension in women. For the current study, to be reported in the January issue of Hypertension and released online December (2012), the team conducted a similar analysis using data from the Physicians' Health Study. The study included (3110) male physicians between the ages of (40) and (84) with previous cholesterol measurements and no history of cerebrovascular or cardiovascular disease, including hypertension, and who had not been treated for hypercholesterolaemia. During median follow-up of (14.1) years, (1019) of the men developed hypertension. After adjusting for age, (BMI), exercise, smoking, alcohol consumption, parental history of (MI) before age (60), and diabetes, men in the highest quintile of (TC) had a (23\%) increased risk of hypertension compared with the lowest quintile ( $\mathrm{p}$ for trend $=0.0067$ ). Those in the highest quintile of (nonHDL-C) had a (39\%) increased risk compared with the lowest quintile $(\mathrm{p}=0.0001)$. Moreover, those in the quintile with the highest calculated (TC/HDL-C) ratio were (54\%) more likely to develop hypertension ( $\mathrm{p}<0.0001$ ). "Elevated lipid levels appear to predate the onset of hypertension by years," Dr. Sesso's group notes. It was suggested that the relationship may be 


\section{INTERNATIONAL JOURNAL of RESEARCH -GRANTHAALAYAH

mediated by atherogenic lipid abnormalities contributing to a dysfunctional endothelium, and that hypertension may be a manifestation of the atherosclerotic process. "By identifying potential risk factors amenable to intervention, may eventually be able to reduce the burden of hypertension and subsequent cardiovascular disease (14).

\section{CONCLUSION}

Increasing lipid abnormality of hypertensive is associated with higher incidence of CAD.

\section{REFERENCES}

[1] Maton A. Human Biology and Health Englewood Cliffs, New Jersey: Prentice Hall; 1993.

[2] McGill HC, Jr., McMahan CA, Zieske AW, et al. Associations of coronary heart disease risk factors with the intermediate lesion of atherosclerosis in youth. The Pathobiological Determinants of Atherosclerosis in Youth (PDAY) Research Group. Arterioscler Thromb Vasc Biol. Aug 2000;20(8):1998-2004.

[3] CDC, US. Chronic Disease Overview: Center for Disease control and Prevention 1999.

[4] Department of Health, Executive Yuan, Taiwan. Health and Vital statistics-vital statistics2005.

[5] Rainwater DL, McMahan CA, Malcom GT, et al. Lipid and apolipoprotein predictors of atherosclerosis in youth: apolipoprotein concentrations do not materially improve prediction of arterial lesions in PDAY subjects. The PDAY Research Group. Arterioscler Thromb Vasc Biol. Mar 1999;19(3):753-761.

[6] Ahmed AM et al. Pattern of hospital mortality among diabetic patients in Sudan. Pract Diab Int March 2000; Vol. 17 No. 2.

[7] Halperin RO. Dyslipidemia and the Risk of Incident Hypertension in Men. Hypertension 2006;47:45-50.

[8] Oparil S, Zaman MA, Calhoun DA. Pathogenesis of hypertension. Ann Intern Med 2003;139:761-776.

[9] Castelli WP, Anderson K. A population at risk. Prevalence of high cholesterol levels in hypertensive patients in the Framingham Study. Am J Med 1986;80:23-32.

[10] Anderson KM, Castelli WP, Levy D. Cholesterol and mortality. 30 years of follow-up from the Framingham study. JAMA 1987;257:2176-2180.

[11] Gaziano JM, Sesso HD, Breslow JL, Hennekens CH, Buring JE. Relation between systemic hypertension and blood lipids on the risk of myocardial infarction. Am J Cardiol 1999;84:768-773.

[12] Haffner SM, Miettinen H, Gaskill SP, Stern MP. Metabolic precursors of hypertension: the San Antonio Heart Study. Arch Intern Med 1996;156: 1994-2000.

[13] Nohria A, Garrett L, Johnson W, Kinlay S, Ganz P, Creager MA. Endothelin-1 and vascular tone in subjects with atherogenic risk factors. Hypertension 2003;42:4348. 


\section{INTERNATIONAL JOURNAL of RESEARCH -GRANTHAALAYAH}

ग्रक्यालयाः A knowledge Repository

Science

[14] Dyslipidemia Can Promote Hypertension in Men. Available on: http://www.diabetesincontrol.com/articles/53-diabetes-news/3355- (Accessed on 24 January 2013). 